\title{
Abnormal DNA methylation patterns in patients with infection-caused leukocytopenia based on methylation microarrays
}

\author{
CHAO WU*, XIRENNAYI MUHATAER ${ }^{*}$, WENYI WANG, MINGQIN DENG, \\ RONG JIN, ZHICHUANG LIAN, DAN LUO, YAFANG LI and XIAOHONG YANG
}

\begin{abstract}
Department of Respiratory and Critical Care Medicine, People's Hospital of Xinjiang Uygur Autonomous Region, Urumqi, Xinjiang Uygur Autonomous Region 830001, P.R. China
\end{abstract}

Received June 18, 2018; Accepted February 07, 2020

DOI: $10.3892 / \mathrm{mmr} .2020 .11061$

\begin{abstract}
The present study aimed to investigate the association between gene methylation and leukocytopenia from the perspective of gene regulation. A total of 30 patients confirmed as having post-infection leukocytopenia at People's Hospital of Xinjiang Uygur Autonomous Region between January 2016 and June 2017 were successively recruited as the leukocytopenia group; 30 patients with post-infection leukocytosis were enrolled as the leukocytosis group. In addition, 30 healthy volunteers who received a health examination at the hospital during the same period were included as the normal control group. In each group, four individuals were randomly selected for whole genome methylation screening. After selection of key methylation sites, the remaining samples in each group were used for verification using matrix-assisted laser desorption/ionization-time of flight mass spectrometry. The levels of serum complement factors C3 and C5 in the leukocytopenia group were significantly lower than those in the other two groups $(\mathrm{P}<0.05)$. According to whole-genome DNA methylation detection, 66 and 27 methylation loci may be associated with leukocytopenia and leukocytosis, respectively. Most of these abnormal loci are located on chromosomes 2, 6, 7, 1, 17 and 11 . The rates of $\mathrm{WW}$ domain containing E3 ubiquitin protein ligase 2 gene methylation at cytosine-phosphate-guanine (CpG)_1, CpG_5/6 and $\mathrm{CpG}_{-} 7$ in the leukocytopenia group were higher than in the other two groups $(\mathrm{P}<0.05)$; the rate of $A K T 2 \mathrm{CpG}_{-} 1$ methylation was higher in the leukocytopenia group than in
\end{abstract}

Correspondence to: Mr. Chao $\mathrm{Wu}$ or Ms. Xiaohong Yang, Department of Respiratory and Critical Care Medicine, People's Hospital of Xinjiang Uygur Autonomous Region, 91 Tianchi Road, Tianshan, Urumqi, Xinjiang Uygur Autonomous Region 830001, P.R. China

E-mail:mail@wu95.com

E-mail: yangxh_16@163.com

*Contributed equally

Key words: bacterial infection, leukocytopenia, methylation, WW domain containing E3 ubiquitin protein ligase 2, gene chip technology the other two groups $(\mathrm{P}<0.05)$; the rate of calcium-binding atopy-related autoantigen 1 gene $\mathrm{CpG}_{2} 2$ methylation was higher in the leukocytosis group than in the normal control group $(\mathrm{P}<0.05)$; and the rate of NADPH oxidase 5 gene $\mathrm{CpG}_{-} 3$ methylation was higher in the leukocytosis group than in the normal control group $(\mathrm{P}<0.05)$. Chemotactic factor secretion and cell migration abnormalities, ubiquitination modification disorders and reduced oxidative burst may participate in infection-complicated leukocytopenia. The results of this study shed new light on the molecular biological mechanisms of infection-complicated leukocytopenia and provide novel avenues for diagnosis and treatment.

\section{Introduction}

Although most patients with infection exhibit leukocytosis, which contributes to rapid inherent immunological defense, a certain portion of these patients experience leukocytopenia (1). In patients with leukocytopenia, pathogens are more likely to escape from immunocytes, increasing the severity of infection symptoms and complicating infection control, thereby prolonging the course of anti-infective treatment (2). Leukocytopenia can be caused by a variety of pathogens, such as bacteria and viruses; however, the detailed mechanisms underlying leukocytopenia post-infection remain unclear $(3,4)$. Numerous studies have demonstrated that gene methylation plays an important role in a variety of pathophysiological processes, and exploration of pathomechanisms from the perspective of gene regulation may provide novel approaches for the diagnosis and treatment of diseases $(5,6)$.

DNA methylation refers to the process via which methyltransferases modify 5 ' terminal promoter region bases and the pentacoordinate carbon of cytosine-phosphate-guanines (CpGs) in the first exon to form 5-methylcytosine (7). A CpG island refers to a region with a $\mathrm{CpG}$ sequence density that is 10-20 times higher than the average density of the sequence, with $>50 \% \mathrm{G}+\mathrm{C}$ content in a region $>200$ bases; $\sim 50 \%$ of human genes contain $\mathrm{CpG}$ islands, for $\sim 29,000$ total $\mathrm{CpG}$ islands, which are normally located in the promoter region of the gene (8). In normal cells, CpG islands exist in a non-methylated state; however, high levels of methylation at $\mathrm{CpG}$ islands in housekeeping genes and tissue-specific genes are closely associated with inactivation of protein function and the 
development of cancers and genetic diseases (9). Furthermore, methylation of $\mathrm{CpG}$ islands in some non-promoter regions, including intragenic, intergenic and downstream regions, may also cause pathological changes at the molecular level (10).

Previous studies on methylation have primarily focused on tumors $(5,9)$; to the best of our knowledge, the role of DNA methylation in leukocytopenia after infection has not been reported. Overall, studying the methylation of single genes is laborious and inefficient, and it fails to reflect the epigenetic variations in patients with post-infection leukocytopenia. Furthermore, a large amount of work would be required to verify individual candidate methylation-regulated genes to determine whether they cause molecular changes in patients with post-infection leukocytopenia. Gene chip technology, also known as microarray technology, is a systematic, complete analytical method specific for DNA methylation (11). Advantages of this method include easy operation and high throughput (11). Indeed, detection of methylation patterns based on this technique has been reported in a number of studies $(11,12)$.

The present study aimed to apply gene chip technology to investigate the association of DNA methylation with post-infection leukocytopenia. To this end, baseline data, inflammation indices and chemotactic factors of patients with post-infection leukocytopenia were analyzed, and the methylation status of the entire genome was analyzed using $450 \mathrm{~K}$ methylation chips to establish gene methylation patterns associated with these patients. Key methylated gene sites were then screened and verified.

\section{Materials and methods}

Study subjects. A total of 30 patients who were diagnosed with infection complicated by leukocytopenia $\left(<3.5 \times 10^{9} / 1\right.$ leukocytes; mean age, 52.34 \pm 12.74 years; age range, 39-65 years) at People's Hospital of Xinjiang Uygur Autonomous Region (Urumqi, China), were successively recruited between January 2016 and June 2017. Patients with leukocytosis ( $>3.5 \times 10^{9} / 1$ leukocytes; $\mathrm{n}=30$; mean age, $53.62 \pm 13.08$ years; age range, 39-66 years) were also enrolled. The control group was comprised of 30 healthy volunteers (mean age, $55.76 \pm 11.84$ years; age range, 43-67 years) who underwent a health examination at the same hospital during the same period. The clinical data of the participants were analyzed. From each group, four individuals were randomly selected for gene-related examination, and the four with leukocytopenia (designated as A1-A4; $\mathrm{n}=4$ ), four with leukocytosis (C1-C4; $\mathrm{n}=4$ ) and four healthy volunteers (D1-D4; $n=4)$ constituted the leukocytopenia, leukocytosis and normal control groups, respectively. Patients with infection due to unknown pathogens or with non-respiratory infection were excluded from the leukocytopenia group; those with leukocytopenia due to chemoradiation, hematological disease or sulfonamide and analgesic medication were excluded from the leukocytopenia group; and those with diseases that influence $\mathrm{C} 3$ and $\mathrm{C} 5$ levels (such as rheumatoid arthritis, idiopathic interstitial pneumonia, chronic bronchitis and bronchial asthma) were excluded from all groups. The 30 patients with leukocytopenia were further divided into slight $\left(<1.5 \times 10^{9} / 1 ; \mathrm{n}=9\right)$, moderate $\left(2.5-1.5 \times 10^{9} / 1\right.$; $\mathrm{n}=15)$ and severe $\left(1.5 \times 10^{9} / 1 ; \mathrm{n}=6\right)$ subgroups, according to the degree of decrease in white blood cell count (13).
This study was conducted in accordance with the Declaration of Helsinki. Approval was obtained from the Ethics Committee of People's Hospital of Xinjiang Uygur Autonomous Region (policy no. 2016056). Written informed consent was obtained from each participant.

Data collection. General data, including sex, age and infection site, were collected for each patient. Clinical data, laboratory examination outcomes with regard to blood routine examination, $\mathrm{C} 3$ and $\mathrm{C} 5$ complement levels, procalcitonin (PCT) and interleukin (IL)- 6 were also collected. In total, $\sim 4 \mathrm{ml}$ of peripheral venous blood was extracted from each participant after fasting and combined with $0.109 \mathrm{~mol} / \mathrm{l}$ sodium citrate anticoagulant agent. The samples were immediately stored at $-196^{\circ} \mathrm{C}$ after collection.

C3 and C5 detection. C3 and C5 serum levels were detected using ELISA. Kits for human serum C3 and C5 detection were purchased from Shanghai Fusheng Industrial Co., Ltd. (cat. no. YM-YM10444), the procedures were performed in strict accordance with the instructions of the manufacturer.

Locations of $C p G$ sites with differential methylation. Sites with differential methylation were classified into transcription start sites (TSS)200, 5'untranslated region (UTR), body, TSS1500, 3' UTR and 1st exon categories according to the physical locations of the detected sites, as well as the related annotation information were provided by the University of California Santa Cruz database (14).

\section{Whole-genome methylation detection}

DNA preparation and quality examination. Genomic DNA was extracted from blood samples using a Wizard ${ }^{\circledR}$ Genomic DNA Purification kit (Promega Corporation), quantified by spectrophotometry and adjusted to the standard concentration of $50 \mathrm{ng} / \mu \mathrm{l}(20 \mu \mathrm{l}$ in total). The sample was subjected to $0.8 \%$ agarose gel electrophoresis. Methylation experiments were performed using samples with a distinct major electrophoresis band with a length no shorter than $10 \mathrm{~kb}$ and no noticeable degradation, with a total sample quantity of $>5 \mu \mathrm{g}$.

Sulfite transformation. Sulfite transformation was performed using an EZ DNA methylation kit (Zymo Research Corp.) according to the manufacturer's protocols.

$\mathrm{NaOH}$ denaturation and whole-genome amplification. $\mathrm{NaOH}(0.1 \%)$ was used to dissociate double-stranded DNA into single-stranded DNA. Whole-genome amplification was performed using a PCR amplification kit (cat. no. KG203; Beijing Hongyue Biotech Co., Ltd.). The amplification conditions were as follows: $94^{\circ} \mathrm{C}$ for $12 \mathrm{~min} ; 10$ cycles of $93^{\circ} \mathrm{C}$ for $50 \mathrm{sec}, 62^{\circ} \mathrm{C}$ for $48 \mathrm{sec}\left(-0.5^{\circ} \mathrm{C} /\right.$ cycle $)$ and $72^{\circ} \mathrm{C}$ for $1 \mathrm{~min}$; 35 cycles of $94^{\circ} \mathrm{C}$ for $45 \mathrm{sec}, 56^{\circ} \mathrm{C}$ for $48 \mathrm{sec}$ and $72^{\circ} \mathrm{C}$ for $1 \mathrm{~min}$; $72^{\circ} \mathrm{C}$ for $3 \mathrm{~min}$; and hold at $4^{\circ} \mathrm{C}$. After amplification, $2 \%$ agarose gel electrophoresis was performed for product verification.

DNA segmentation, precipitation and resuspension. PCR products were fragmented using the random endonuclease method. Isopropanol was applied for centrifugal precipitation of the fragments at $4^{\circ} \mathrm{C}\left(2 \times 10^{4} \mathrm{xg}\right.$ for $\left.15 \mathrm{~min}\right)$. The precipitated 
sample was placed at room temperature, dried and dissolved in hybridization buffer.

DNA/chip hybridization. Prepared chips were used for DNA hybridization. The capture probe with 50-mer-long beads ( $7 \mathrm{fmol} / \mu \mathrm{l})$ was combined with the digested genomic DNA (gDNA) products; annealing was carried out in a hybridization oven for 8-10 h.

Chip washing and single-base extension and staining. The wash rack was submerged in the wash dish containing $200 \mathrm{ml}$ PB1 (Shanghai Tichem Chemical Co., Ltd.). The Hyb Chamber inserts were removed from the Hyb Chambers. BeadChips (CapitalBio Corporation) were removed from the Hyb Chamber inserts one at a time, and the cover seal was removed from each BeadChip. Then, the BeadChip was slide into the wash rack, one at a time, ensuring that the BeadChip was complete. These procedures were repeated until all BeadChips (a maximum of 8) were transferred to the wash rack submerged in PB1. Once all BeadChips were in the wash rack, the wash rack was moved up and down for $1 \mathrm{~min}$, the surface of the PB1 was broken with gentle, slow agitation. The wash rack was transferred to the other wash dish containing clean PB1 (ensuring all BeadChips were complete) and the wash rack was moved up and down for 1 min. The surface of the PB1 was broken with gentle, slow agitation. The DNA sequence detected by the probe was used as the template, and nucleotide substrates were labeled with dinitrophenol and biotin using the random primer method (A/T and $\mathrm{C} / \mathrm{G}$, respectively) (15) Unqualified DNA was removed, followed by single base extension (the condition for base extension was that gDNA hybridization did not occur). Detectable fluorophores (Fluorescein-5-maleimide) were applied to the chip, and $\mathrm{A} / \mathrm{T}$ and $\mathrm{C} / \mathrm{G}$ were used for labeling different fluorescent dyes to distinguish different methylation states. The chip was coated with XC4 reagent to prolong its lifetime and the extension time of the signals. The chip was then placed in a vacuum dehydration unit for $1 \mathrm{~h}$.

Chip scanning and data reading. The fluorophores were excited with a laser to obtain fluorescence. Corresponding 'manifest' files were downloaded (https://support.illumina. com/downloads/infinium-methylationepic-v1-0-product-files. html) to generate raw data. The data were then analyzed using GenomeStudio software (version 1.1.0; Illumina, Inc.) to obtain the methylation P-value of each gene and each site of the gene $(16,17)$.

Key site screening. To obtain the genes associated with leukocytopenia, the scope of key gene site screening was narrowed by intersection analysis (18). Based on P-values and the functions of related genes according to GenBank (https://www.ncbi.nlm.nih. gov/; accessed on February 18, 2018), AKT2, NADPH oxidase 5 (NOX5), WW domain containing E3 ubiquitin protein ligase2 (WWP2) and calcium-binding atopy-related autoantigen 1 (CBARAl) were ultimately selected for verification.

\section{Key gene verification}

DNA preparation. DNA was extracted from blood samples using a Wizard Genomic DNA Purification kit (Promega Corporation). Quantitation using spectrophotometry and 1\% agarose gel electrophoresis was performed. In general, the length of gDNA obtained was no shorter than $20 \mathrm{~kb}$. DNA was adjusted to a concentration of $50 \mathrm{ng} / \mu \mathrm{l}$ and transferred to a 384-well plate for storage at $-20^{\circ} \mathrm{C}$.

Primer design. Primers were designed by EpiDesigner (Sequenom; http://www.epidesigner.com) to correspond to the methylation sites of AKT2, NOX5,WWP2 and CBARA1. The normal lengths of the amplified fragments ranged from 200-600 bp. To the 5' terminal of the forward primer, 10-mer tag was applied to balance PCR conditions, and a $\mathrm{T} 7$ promoter sequence was applied to the $5^{\prime}$ terminal of the reverse primer for subsequent transcription in vitro. Syntheses were performed by CapitalBio Technology Co., Ltd. The upstream and downstream primers of $A K T 2$ were 5'-TTT ATGTAAAGAGGAATAGTTGGGAAA-3' and 5'-CCA AAA AAACAACAAAAATTCACTC-3', respectively. After modification, the upstream and downstream primers were 5'-aggaagagagTTTATGTAAAGAGGAATAGTTGGG AAA-3' and 5'-cagtaatacgactcactatagggagaaggctCCAAAA AACAACAAAAATTCACTC-3', respectively. The upstream, downstream, modified upstream and modified downstream primers of NOX5 were 5'-TGGGGTATTTATTTTTAA AGTGGGT-3', 5'-AATCAATCCACTACACTCCAACCT A-3', 5'-aggaagagagTGGGGTATTTATTTTTAAAGTGGG T-3' and 5'-cagtaatacgactcactatagggagaaggetAATCAATCCACTACACTCCAACCTA-3', respectively. The upstream, downstream, modified upstream and modified downstream primers of $W W P 2$ were 5'-TGGGGTATTTATTTTTAAAGT GGGT-3', 5'-AAA ACCAAA AACAAATTAACCCAA-3', 5'-aggaagagagTTTTGGATAGTAGGGTAGAAGGGTT-3' and 5'-cagtaatacgactcactatagggagaaggctAAAACCAAAAAC AAATTAACCCAA-3', respectively, and those of CBARA1 were 5'-GGTATGTGTGTTTTTTGGAGAGAGTT-3', 5'-ATCAAACAAAATAAA ACCAACAAAT-3', 5'-aggaag agagGGTATGTGTGTTTTTTGGAGAGAGTT-3' and 5'-cag taatacgactcactatagggagaaggctATCAAACAAAATAAAACC AACAAAT-3', respectively.

PCR amplification. Amplification was performed using a PCR amplification kit (Sequenom). The amplification conditions consisted of $94^{\circ} \mathrm{C}$ for $12 \mathrm{~min}, 10$ cycles at $93^{\circ} \mathrm{C}$ for $50 \mathrm{sec}$, $62^{\circ} \mathrm{C}$ for $48 \mathrm{sec}\left(-0.5^{\circ} \mathrm{C} /\right.$ cycle $)$ and $72^{\circ} \mathrm{C}$ for $1 \mathrm{~min}, 35$ cycles at $94^{\circ} \mathrm{C}$ for $45 \mathrm{sec}, 56^{\circ} \mathrm{C}$ for $48 \mathrm{sec}$ and $72^{\circ} \mathrm{C}$ for $1 \mathrm{~min}, 72^{\circ} \mathrm{C}$ for 3 min and a final hold at $4^{\circ} \mathrm{C}$. Agarose gel $(2 \%)$ electrophoresis was performed for PCR product verification, with ethidium bromide as the fluorescence dye. RT fluorescent quantitation was performed for PCR products.

Shrimp alkaline phosphatase (SAP). SAP treatment was performed in accordance with the instructions of the MassCLEAVE ${ }^{\mathrm{TM}}$ reagent kit (Sequenom).

Chip sample application and mass spectrometric detection. Purified products were applied to a 384-formatted SpectroCHIP with the MassARRAYNanodispenser RS1000 arrayer (Sequenom). The prepared chip was detected using a MassARRAY compact system (Sequenom). Matrix-assisted laser desorption/ionization-time of flight mass spectrometry was performed in accordance with the protocols of the 
Table I. General data for the three groups.

\begin{tabular}{|c|c|c|c|c|}
\hline Characteristics & Leukocytopenia $(\mathrm{n}=30)$ & Leukocytosis $(\mathrm{n}=30)$ & Normal control $(n=30)$ & P-value \\
\hline Age (years) & $52.34 \pm 12.74$ & $53.62 \pm 13.08$ & $55.76 \pm 11.84$ & $0.349^{\mathrm{a}}$ \\
\hline Sex & & & & $0.084^{\mathrm{a}}$ \\
\hline Male & 16 & 19 & 15 & \\
\hline Female & 14 & 11 & 15 & \\
\hline Infection site & & & & $0.074^{\mathrm{b}}$ \\
\hline Pulmonary & 13 & 11 & 0 & \\
\hline Hematogenous & 3 & 7 & 0 & \\
\hline Intra-abdominal & 4 & 3 & 0 & \\
\hline Pathogen & & & & $0.026^{\mathrm{b}}$ \\
\hline Gram-positive cocci & 11 & 15 & 0 & \\
\hline Gram-negative cocci & 9 & 4 & 0 & \\
\hline Other bacteria & 0 & 0 & 0 & \\
\hline Virus & 0 & 0 & 0 & \\
\hline No etiological base & 10 & 11 & 30 & \\
\hline Died within $72 \mathrm{~h}$ after admission & 3 & 1 & 0 & \\
\hline
\end{tabular}

Data are presented as the mean $\pm \mathrm{SD}$, or $\mathrm{n} .{ }^{\mathrm{a}}$ comparison of three groups; ${ }^{\mathrm{b}}$ comparison of leukocytopenia and leukocytosis groups only. $\mathrm{SD}$, standard deviation; h, hours.

Infinium HD Assay Methylation Protocol Guide 2011 (19), and data were analyzed using EpiTYPER v1.05 (Sequenom).

\section{Statistical analysis}

Genomic methylation data. Raw data were processed by GenomeStudio software to obtain the original signal value and detection P-value of each site $(15,16)$. Site quality control and individual quality control were performed. Color bias adjustment and quantile normalization were performed for the quality-controlled data using Lumi 2.22.1 included in the $\mathrm{R}$ software 4.0.0 package $(20,21)$. For probe-type biases, the methylation levels ( $\beta$ values) obtained after the preceding adjustment step were further adjusted with BMIQ v1.3 ( $\beta$-mixture quantile normalization). The adjusted $\beta$ values were subjected to differential methylation analysis using IMA 3.1.2 of the R software package (22), and the analysis method was based on the limma algorithm (23) of Empirical Bayes Statistics. For multiple hypothesis testing, the P-value adjusted by the false discovery rate (FDR) was calculated using the Benjamini-Hochberg method (24). The selection criterion for differential sites was an adjusted P-value (FDR value) $\leq 0.05$ (if the adjusted P-values of all sites were $>0.05$ or when the adjusted P-values of few sites were $\leq 0.05$, a P-value before adjustment of $\leq 0.05$ was used as the criterion). Cluster analysis was performed for the samples using gplots 2.13.0 of the R package (https://CRAN.R-project. org/package=gplots). Gene Ontology (GO) enrichment $(25,26)$, Kyoto Encyclopedia of Genes and Genomes (KEGG) pathway enrichment (27) and disease enrichment [Online Mendelian Inheritance in Man (OMIM), KEGG Disease, FunDo, GAD, National Human Genome Research Institute (NHGRI)] analyses were performed for the genes mapped based on differential sites.
Other data. Experimental data were processed using SPSS 22.0 software (IBM Corp.). For categorical data, $\chi^{2}$ test was used for group comparisons. For data regarding methylation levels and serum testing, one-way ANOVA was used for comparison among groups. When measurement data were abnormally distributed or exhibited heterogeneity of variance [PCT, C-reactive protein (CRP), acute physiology and chronic health evaluation II (APACHE II) score, C3], the nonparametric Kruskal-Wallis one-way ANOVA was applied for comparison of methylation levels among groups. The significance level was adjusted using the Bonferroni method, and an adjusted $\mathrm{P}<0.05$ was considered significant (all stated $\mathrm{P}$-values are adjusted). GraphPad Prism 6 (GraphPad Software, Inc.) was used for plotting.

\section{Results}

\section{General data}

Clinical data. Clinical data for patients with post-infection leukocytopenia or post-infection leukocytosis, and for normal controls were analyzed (Table I). The confirmation of infection was based on etiological outcomes or an increase in PCT levels. The three groups did not show significant differences in age $(\mathrm{F}=1.026, \mathrm{P}=0.349)$ or sex ratio $\left(\chi^{2}=5.217\right.$, $\mathrm{P}=0.084)$. Similarly, the leukocytopenia and leukocytosis groups did not show significant differences in infection sites $\left(\chi^{2}=4.692, \mathrm{P}=0.074\right)$ or infectious pathogen type $\left(\chi^{2}=7.631\right.$, $\mathrm{P}=0.062)$.

Diagnostic values of inflammation indices for post-infection leukocytopenia and leukocytosis. The leukocytopenia group had significantly higher levels of PCT and IL-6 than the leukocytosis group $(\mathrm{P}=0.015$ and $\mathrm{P}=0.034$, respectively); however, 
Table II. Comparisons of inflammation indices between post-infection leukocytopenia and post-infection leukocytosis.

\begin{tabular}{lccc}
\hline Index & Leukocytopenia & Leukocytosis & P-value \\
\hline PCT, $\mathrm{ng} / \mathrm{ml}$ & $4.6(0.4,8.2)$ & $7.2(0.6,30.3)$ & 0.015 \\
$\mathrm{CRP}, \mathrm{mg} / \mathrm{ml}$ & $86.2(40.6,130.4)$ & $67.6(30.1,116.7)$ & 0.961 \\
$\mathrm{IL}-6, \mathrm{pg} / \mathrm{ml}$ & $6.25 \pm 1.26$ & $9.43 \pm 3.08$ & 0.034 \\
\hline
\end{tabular}

PCT and CRP are presented as median (interquartile range). IL-6 is presented as mean \pm SD. PCT, procalcitonin; CRP, C-reactive protein; IL, interleukin; SD, standard deviation.

Table III. Analysis of associations between inflammation indices and total white blood cell counts in leukocytopenia.

\begin{tabular}{|c|c|c|c|c|}
\hline Index & Slight $(\mathrm{n}=9)$ & Moderate $(\mathrm{n}=15)$ & Severe $(n=6)$ & P-value \\
\hline $\mathrm{PCT}, \mathrm{ng} / \mathrm{ml}$ & $2.9(0.92,7.9)$ & $3.8(1.28,8.3)$ & $4.3(1.7,9.6)$ & 0.023 \\
\hline $\mathrm{CRP}, \mathrm{mg} / \mathrm{ml}$ & $60.2(33.6,103.2)$ & $68.4(36.7,116.3)$ & $73.2(40.6,128.9)$ & 0.231 \\
\hline IL-6, pg/ml & $6.3 \pm 0.8$ & $7.9 \pm 1.9$ & $8.6 \pm 2.3$ & 0.118 \\
\hline APACHE II score & $18.9(14.9,19.3)$ & $19.7(15.3,21.3)$ & $20.2(16.7,25.6)$ & 0.031 \\
\hline
\end{tabular}

PCT and CRP are presented as median (interquartile range). IL-6 is presented as mean \pm SD. PCT, procalcitonin; CRP, C-reactive protein; IL, interleukin.

Table IV. Comparisons of C3 and C5 levels.

\begin{tabular}{|c|c|c|c|c|}
\hline Index & Leukocytopenia & Leukocytosis & Normal control & P-value \\
\hline C3, g/l & $0.26(0.08,1.45)$ & $1.48(0.76,1.65)$ & $0.9(0.88,1.39)$ & 0.026 \\
\hline C5, g/1 & $0.7 \pm 0.38$ & $1.4 \pm 0.46$ & $3.1 \pm 1.5$ & 0.031 \\
\hline
\end{tabular}

Data are presented as mean \pm SD and median (interquartile range).

no significant difference in CRP levels was observed between these two groups $(\mathrm{P}>0.05$; Table II).

Association of inflammation indices with the total white blood cell count in leukocytopenia. The 30 patients with leukocytopenia were further divided according to the degree of decrease. The highest serum PCT level was observed in the severe group, followed by the moderate group and the slight group $(\mathrm{P}<0.05)$. No significant differences in IL-6 and CRP were observed among the three groups. The highest APCACHE II score was observed in the severe group, followed by the moderate group and the slight group $(\mathrm{P}<0.05)$. The results are summarized in Table III.

Changes in serum C3 and C5. C3 and C5 levels in the leukocytopenia, leukocytosis and normal control groups were detected by ELISA. The leukocytopenia group showed significantly lower levels of C3 and C5 than the leukocytosis and the normal control groups (all $\mathrm{P}<0.05$; Table IV).

\section{Methylation levels}

Cp $G$ sites and genes with differential methylation. Methylation levels were detected at 473,270 sites across the leukocytopenia, leukocytosis and normal control groups. Pairwise comparisons of methylation rates were performed among the three groups, and the results are shown in Fig. 1. The comparison between the eukocytopenia group and the leukocytosis group demonstrated significantly more hyper- methylation sites compared with hypo-methylation sites, and the comparison between the leukocytosis group and the normal control group found less hyper- methylation sites compared with hypo-methylation sites. However, there were no significant difference between the number of hyper- methylation sites and that of hypo-methylation sites when the leukocytopenia group was compared with the normal control group.

Locations of CpG sites with differential methylation. Methylation of the TSS, 5' UTR and 1st exon inhibits gene expression, whereas that of the body and 3' UTR promotes expression. The results are shown in Fig. 2. A total of 24,230 differential methylation sites were detected between the leukocytopenia group and the leukocytosis group: 11,796 sites were related to the genes whose methylation inhibits gene expression and 9,416 were related to the genes whose methylation promotes gene expression, with the rest undetected in genes. There were 26,892 differential methylation sites detected in total between the leukocytosis group and 
A a

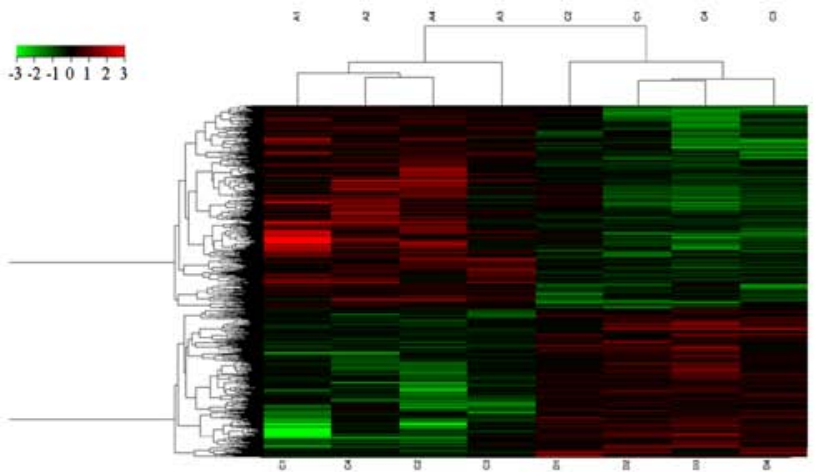

B a

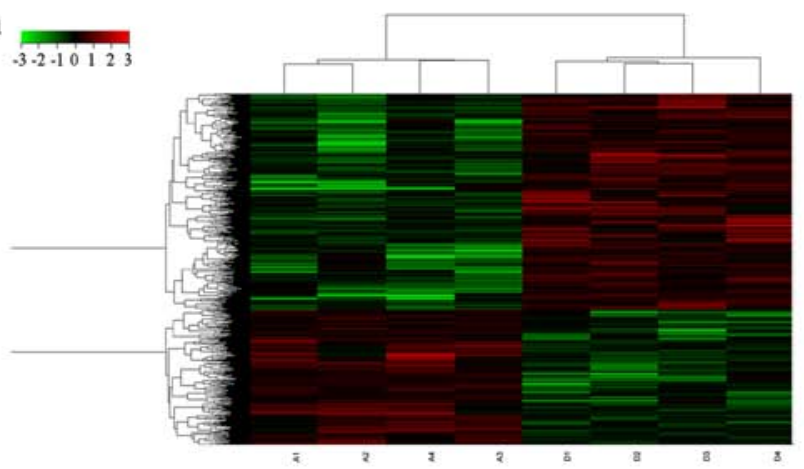

$\mathrm{C}$ a

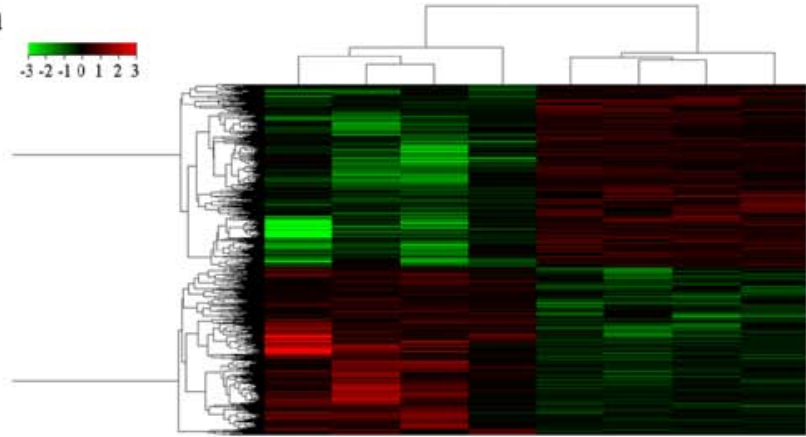

b

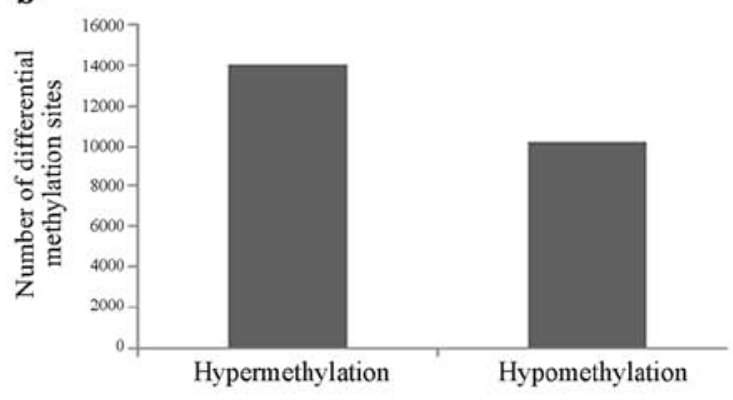

b
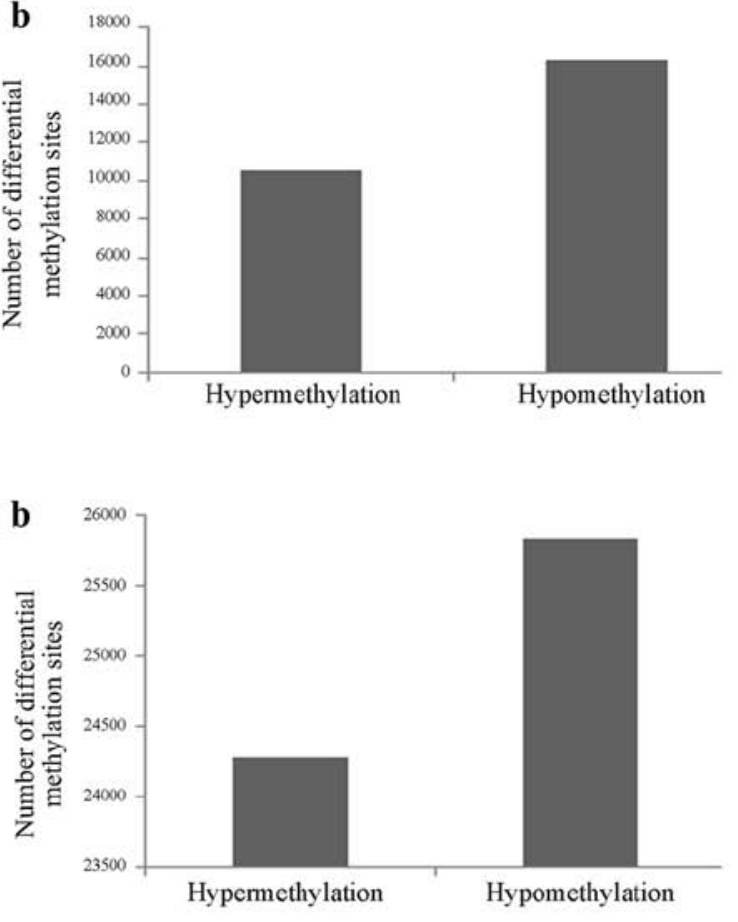

Figure 1. Methylation dendrograms of the three groups and pairwise comparisons of overall methylation levels. (A) Leukocytopenia (designated as A1-4) vs. leukocytosis (C1-4): 24,230 differential methylation sites were observed. (Aa) Difference in methylation levels between the two groups; (Ab) comparison between the leukocytosis group and the leukocytopenia group had more hypermethylated genes than hypomethylated genes. (B) Leukocytosis vs. normal control (D1-4): 26,892 differential methylation sites were observed. (Ba) Difference in methylation levels between the two groups; (Bb) comparison between the normal control group and the leukocytosis group identified more hypomethylated genes than hypermethylated genes. (C) Leukocytopenia vs. normal control: 50,117 differential methylation sites were observed. (Ca) Difference in methylation levels between the two groups; (Cb) comparison between the normal control group and the leukocytopenia group demonstrated noticeably more hypomethylated genes than hypermethylated genes.
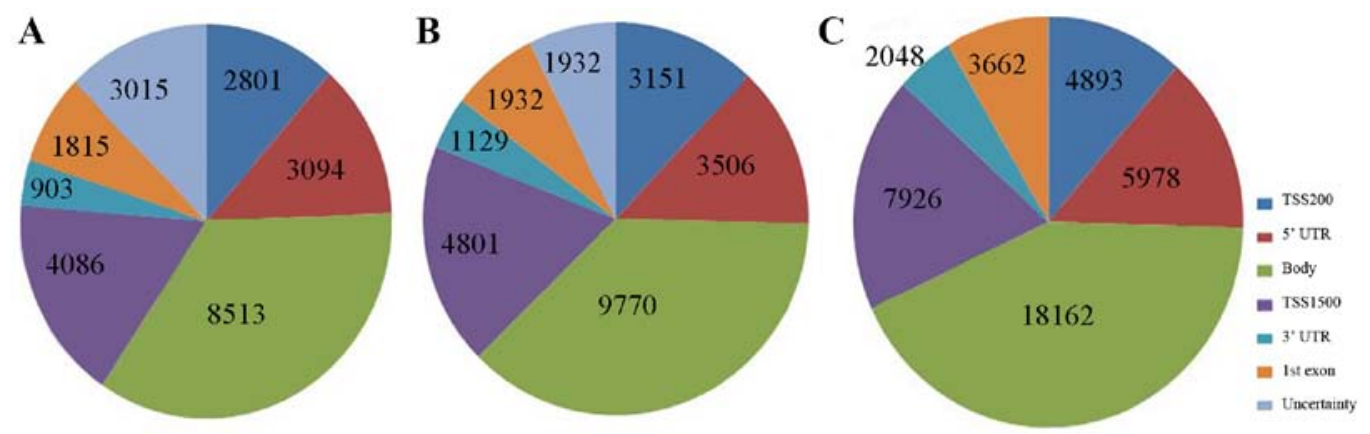

Figure 2. Pie charts of CpG sites with differential methylation between the three groups. (A) leukocytopenia vs. leukocytosis. (B) Leukocytosis vs. normal control. (C) leukocytopenia vs. normal control. CpG, cytosine-phosphate-guanine; UTR, untranslated region.

the normal control group: 13,390 sites were related to the genes whose methylation inhibits gene expression and 10,899 were related to the genes whose methylation promotes gene expression, with the rest undetected in genes. Moreover, 
Table V. Chromosome distribution of sites with differential methylation.

\begin{tabular}{|c|c|c|c|}
\hline Chromosome no. & Leukocytopenia vs. leukocytosis (n, \%) & Leukocytosis vs. control (n, \%) & Leukocytopenia vs. control (n, \%) \\
\hline 1 & $1,561(6.44)$ & $1,809(6.73)$ & $1,809(6.73)$ \\
\hline 2 & $2,564(10.58)$ & $2,791(10.38)$ & $3,848(7.68)$ \\
\hline 3 & $1,390(5.73)$ & $1,365(5.08)$ & $2,690(5.37)$ \\
\hline 4 & $1,205(5.10)$ & $1,165(4.33)$ & $2,370(4.73)$ \\
\hline 5 & $1,296(5.35)$ & $1,355(5.04)$ & $2,732(5.45)$ \\
\hline 6 & $1,990(8.21)$ & $2,235(8.31)$ & $3,810(7.60)$ \\
\hline 7 & $1,558(6.43)$ & $1,643(6.11)$ & $3,163(6.31)$ \\
\hline 8 & $1,080(4.46)$ & $1,179(4.38)$ & $2,389(4.77)$ \\
\hline 9 & $0(0.00)$ & $581(2.16)$ & $1,046(2.09)$ \\
\hline 10 & $1,259(5.20)$ & $1,438(5.34)$ & $2,650(5.29)$ \\
\hline 11 & $1,424(5.88)$ & $1,538(5.72)$ & $3,167(6.32)$ \\
\hline 12 & $1,228(5.11)$ & $1,423(5.29)$ & $2,491(4.97)$ \\
\hline 13 & $0(0.00)$ & $690(2.57)$ & $1,245(2.48)$ \\
\hline 14 & $754(3.11)$ & $781(2.90)$ & $1,580(3.15)$ \\
\hline 15 & $819(3.40)$ & $888(3.30)$ & $1,667(3.33)$ \\
\hline 16 & $1,025(4.23)$ & $1,273(4.73)$ & $2,142(4.27)$ \\
\hline 17 & $1,261(5.20)$ & $1,672(6.22)$ & $2,695(5.38)$ \\
\hline 18 & $329(1.41)$ & $299(1.11)$ & $0(0.00)$ \\
\hline 19 & $1,211(5.10)$ & $1,432(5.33)$ & $2,291(4.57)$ \\
\hline 20 & $515(2.13)$ & $611(2.27)$ & $1,070(2.14)$ \\
\hline 21 & $234(0.01)$ & $223(0.01)$ & $440(0.88)$ \\
\hline 22 & $370(0.02)$ & $501(1.86)$ & $798(1.59)$ \\
\hline
\end{tabular}

comparison between the leukocytopenia group and the normal control group identified 50,117 differential methylation sites: 22,459 sites were related to the genes whose methylation inhibits gene expression and 20,210 were related to the genes whose methylation promotes gene expression, with the rest undetected in genes.

Chromosome distribution of sites with differential methylation. The chromosome distribution of sites with differential CpG methylation was also analyzed. Sites with differential methylation between the leukocytopenia and leukocytosis groups were primarily located on chromosomes 1, 2, 6 , and 7 . In addition, sites with differential methylation between the leukocytosis and normal control groups were primarily located on chromosomes 2, 6, 7 and 17, and those between the leukocytopenia and normal control groups were primarily located on chromosomes 1, 2, 6 and 11 (Table V).

GO enrichment analysis. GO enrichment categories include biochemical processes, molecular function and cellular composition. The comparison between the leukocytopenia group and the leukocytosis group demonstrated that the three biochemical processes with the P-values with the greatest significance are nervous system development, system development and multicellular organismal development; the three molecular functions with the most strongly significant P-values are binding, sequence-specific DNA binding and sequence-specific DNA binding transcription factor activity; and the three cellular compositions with the $\mathrm{P}$-values with the greatest significance are cell projections, neuron projections and cell junctions (Fig. 3A). Comparing the leukocytosis and normal control groups, the three biochemical processes with the P-values with the greatest significance are cellular component organization or biogenesis, cellular component organization and positive regulation of biological process; the three molecular functions with the P-values with the greatest significance are protein binding, binding and organic cyclic compound binding; and the three cellular compositions with the P-values with the greatest significance are intracellular, intracellular part and cytoplasm (Fig. 3B). The comparison between the leukocytopenia group and the normal control group showed that the three biochemical processes with the $\mathrm{P}$-values with the greatest significance are system development, multicellular organismal development and single-organism developmental process; the three molecular functions with the P-values with the greatest significance are cation channel activity, ion channel activity and passive transmembrane transporter activity; and the three cellular compositions with the P-values with the greatest significance are cell projections, plasma membrane part and extracellular matrix (Fig. 3C).

\section{Pathway analysis}

Leukocytopenia vs. leukocytosis. Signaling pathways with the most significant P-values are associated with Rap1 signaling pathway, cholinergic synapse, circadian entrainment and morphine addiction (Fig. 4). Further disease enrichment with the R software identified that diseases with the most significant P-values were cancer, depression, behavior disease and intestinal disease (Fig. S1) 


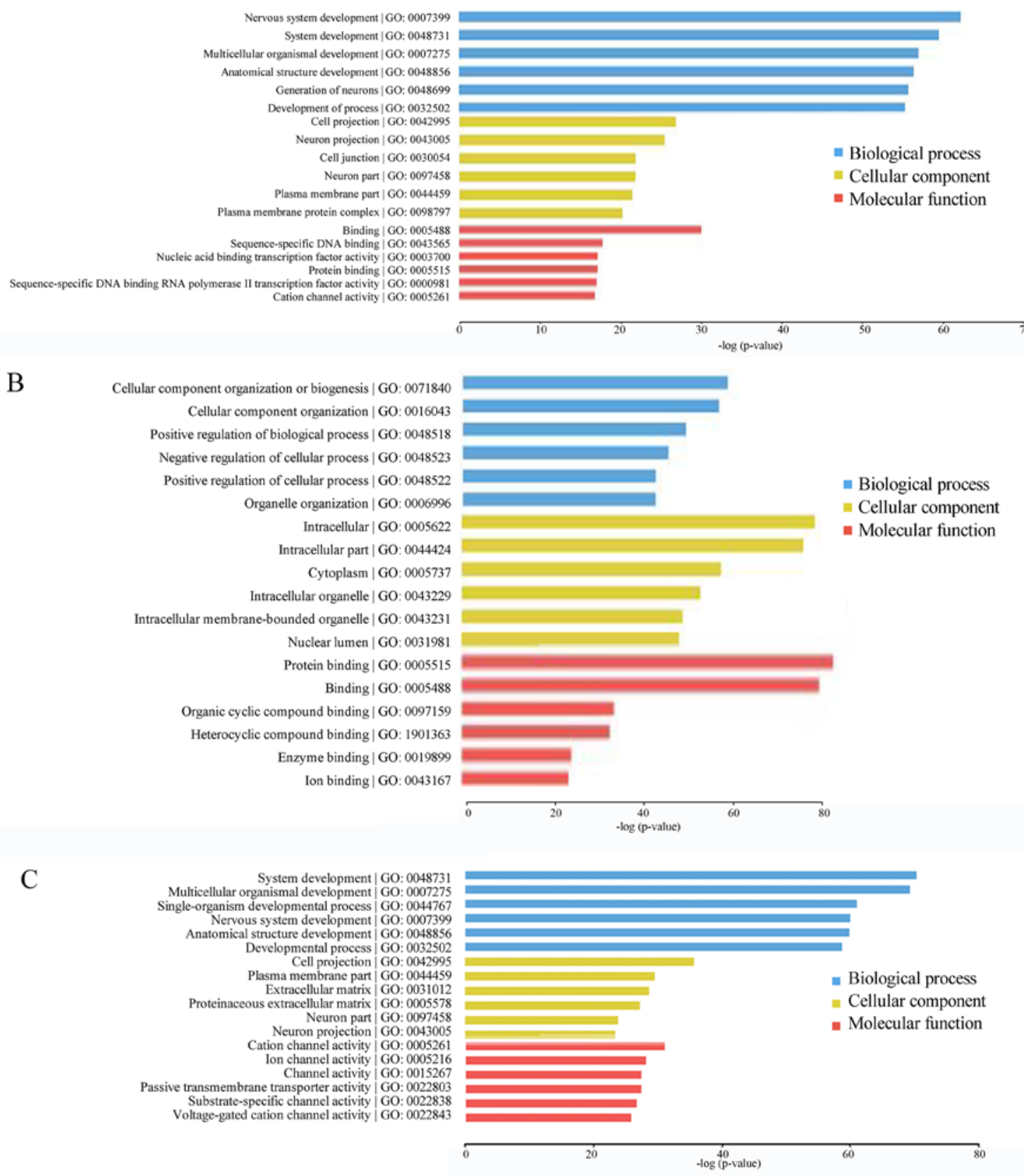

Figure 3. Frequency profiles of second-level entries according to GO enrichment analysis. (A) Leukocytopenia group vs. the leukocytosis group. (B) Leukocytosis group vs. the normal control group. (C) Leukocytopenia group vs. the normal control group. GO, Gene Ontology.

Leukocytopenia vs. normal control. Signaling KEGG pathways with the most significant P-values were pathways in cancer, Axon guidance, focal adhesion and PISK-Akt signaling pathway (Fig. 5). P-values with the greatest significance included cancer, Down syndrome, diabetes mellitus, cholelithiasis, urinary depression, brain disease and drug abuse (Fig. S2).

Leukocytosis vs. normal control. Signaling KEGG pathways with the most significant P-values were associated with Epstein-Barr virus infection, viral myocarditis, focal adhesion, and small cell lung cancer (Fig. 6). Diseases with P-values with the greatest significance included cancer, adenovirus infection, brain tumor, leukoencephalopathy, neurodegenerative disorder and deafness (Fig. S3).

Key site screening. The analysis of the leukocytopenia group vs. the leukocytosis group and the leukocytopenia group vs. the normal control group showed a total of 66 differential sites, which corresponded to 37 genes; both the leukocytopenia group vs. the leukocytosis group and the leukocytopenia group vs. the normal control group had 28 sites with hypermethylation and 38 sites with hypomethylation (Table SI). The analysis for the leukocytopenia group vs. the leukocytosis group, and the leukocytosis group vs. normal control group 


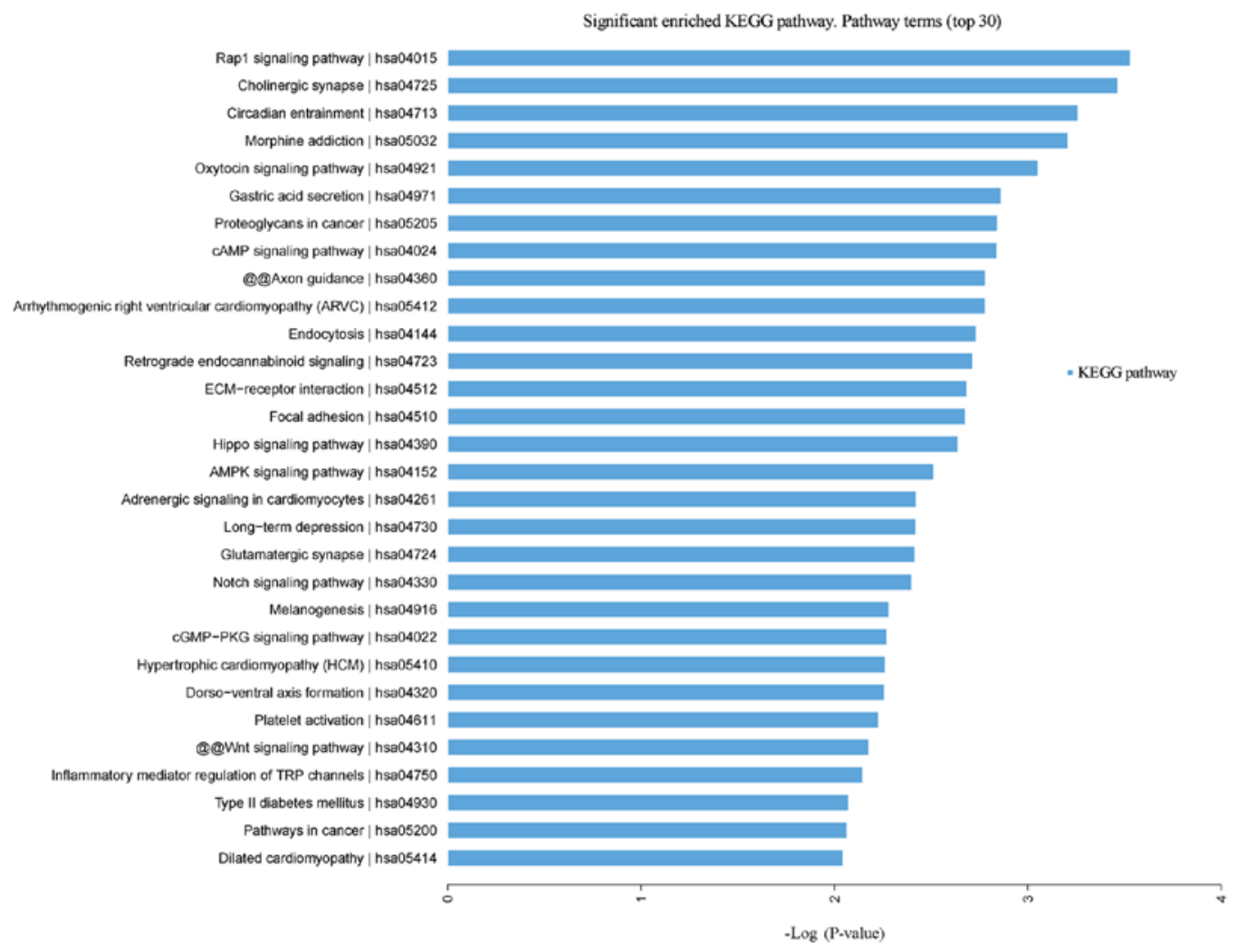

Figure 4. Comparisons of second-level entries between the leukocytopenia group and the leukocytosis group according to KEGG pathway enrichment analysis. KEGG, Kyoto Encyclopedia of Genes and Genomes.

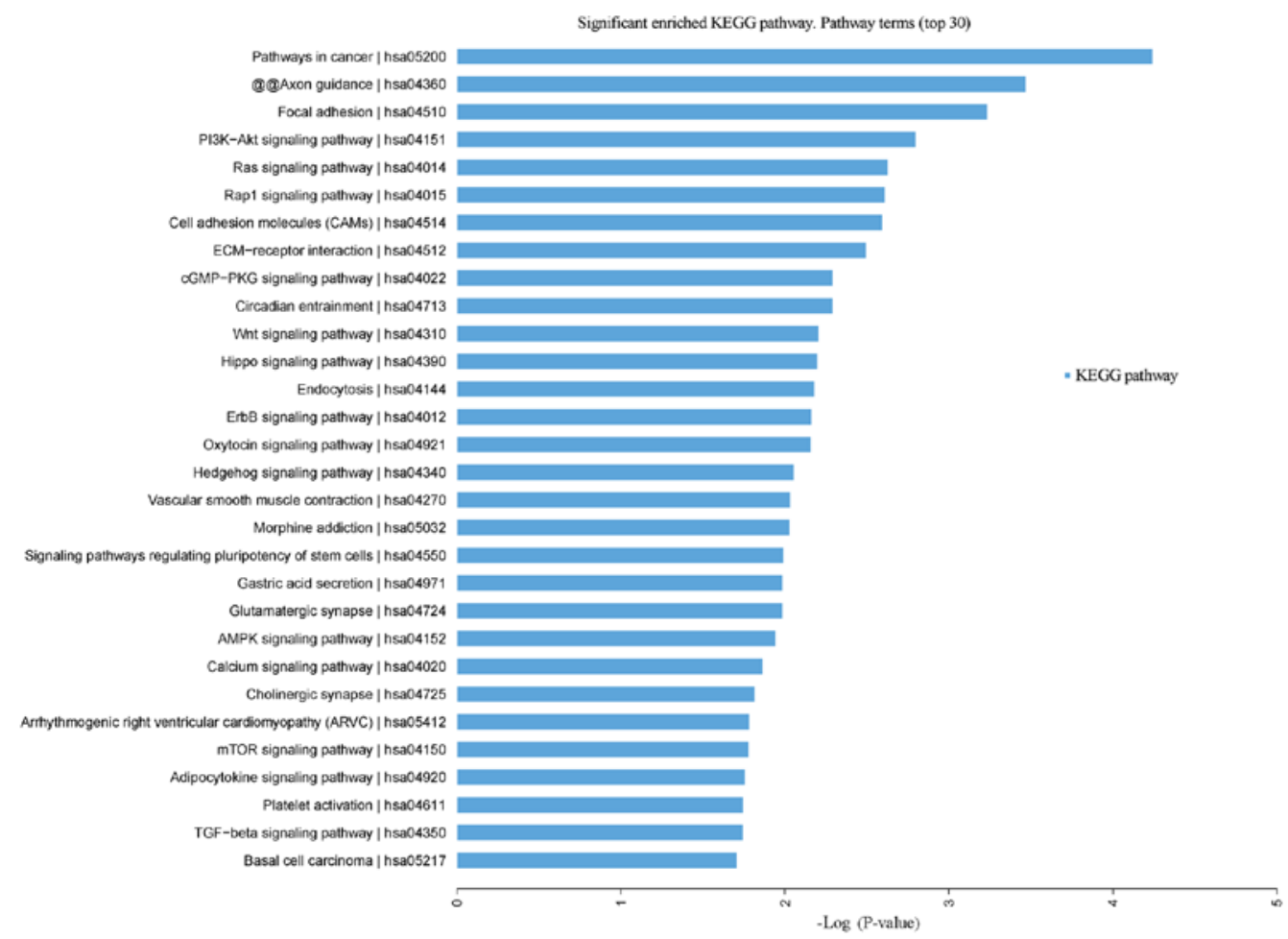

Figure 5. Comparisons of second-level entries between the leukocytopenia group and the normal control group according to KEGG pathway enrichment analysis. KEGG, Kyoto Encyclopedia of Genes and Genomes.

showed 27 significantly different sites, which corresponded to 18 genes. A total of 13 hypermethylated fragments were observed in the leukocytopenia group compared with the leukocytosis group, and 14 were observed in the leukocytosis group compared with the normal control group. A total of 14 hypomethylation fragments were observed in the leukocy- 
Table VI. Key genes.

\begin{tabular}{lccl}
\hline Gene & ILMNID & ADDRESSA_ID & ALLELEA_PROBESEQ \\
\hline$W W P 2$ & $\operatorname{cg} 01735503$ & 73749496 & AAACCAAAAACAAATTAACCCAACACCAAACRAAAAAACATACCCACACC \\
AKT2 & $\operatorname{cg} 07815521$ & 43769440 & ATAAACATAATATATAACCRAACTAATAACTAAAAAACACAAACAACTTC \\
NOX5 & $\operatorname{cg} 26664528$ & 67715503 & TACCCTCATTTAATCCATATATCAAATAAACACRTATTATATTAATTCTC \\
CBARAl & $\operatorname{cg} 06348245$ & 35789301 & ACAACTTAAAAAATATATTCAACAACAATCCAACRAAAAACACATATAAC \\
\hline
\end{tabular}

WWP2, WW domain containing E3 ubiquitin protein ligase 2; NOX5, NADPH oxidase 5; CBARA1, calcium-binding atopy-related autoantigen 1.

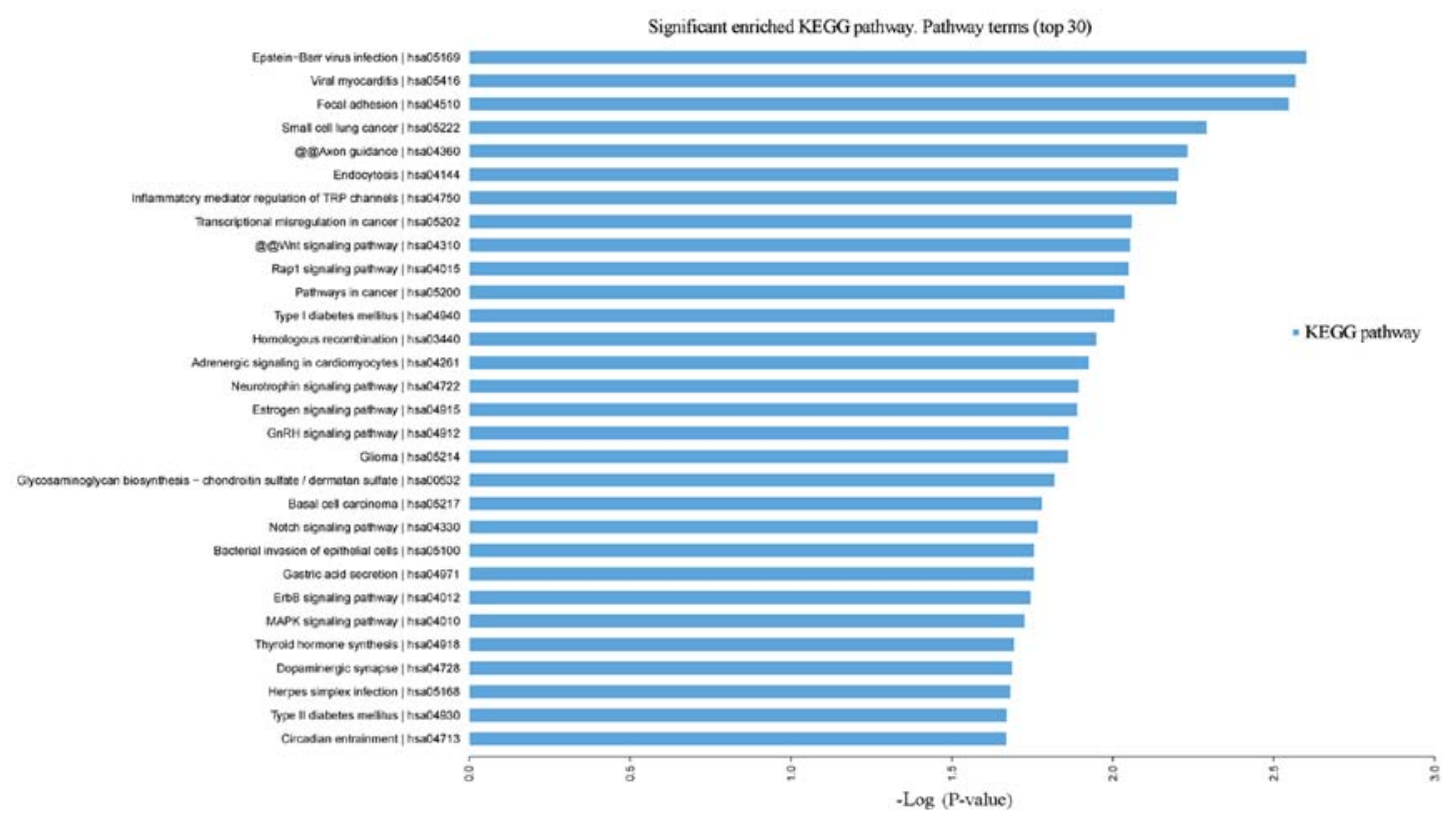

Figure 6. Comparisons of second-level entries between the leukocytosis group and the normal control group according to KEGG pathway enrichment analysis. KEGG, Kyoto Encyclopedia of Genes and Genomes.

topenia group compared with the leukocytosis group, and 13 were observed in the leukocytosis group compared with the normal control group (Table SII).

Based on P-values and the functions of related genes according to GenBank (https://www.ncbi.nlm.nih.gov/; accessed on February 18, 2018), four genes were ultimately selected for verification (Table VI). WWP2 is an E3 ubiquitin protein ligase containing a WW domain that participates in the ubiquitination process and viral entry into host cells (28). $A K T 2$ has shown nucleotide binding, protein serine, threonine kinase, protein binding, ATP-binding and transferase activities, and participates in protein amino acid phosphorylation and diabetes development (29). NOX5 has calcium ion binding, hydrogen ionic channel, oxidation reduction enzyme, hemocrystallin-binding and NADP-binding activities, and participates in cytokinesis, electron transfer, apoptosis, hyperoxide release and cytokine release. CBARAl has been demonstrated to have calcium ion-binding activity and participate in defense responses (30).

Key gene verification

$W W P 2$ gene. A total of five $\mathrm{CpG}$ sites in WWP2 fragments $\left(\mathrm{CpG} \_1, \mathrm{CpG} \_2 / 3, \mathrm{CpG} \_4, \mathrm{CpG}\right.$-5/6 and $\mathrm{CpG}$-7) were inves- tigated, and four ( $\mathrm{CpG} \_1, \mathrm{CpG}$ _2/3, $\mathrm{CpG}$ _5/6 and $\mathrm{CpG}$ _7) were detected (Fig. 7). Although no significant differences in methylation rates at $\mathrm{CpG}_{-} 2 / 3$ were observed among the three groups $(\mathrm{P}=0.350)$, significant differences were observed at $\mathrm{CpG}$ _1, CpG_5/6 and $\mathrm{CpG}_{-} 7(\mathrm{P}=0.010, \mathrm{P}=0.002$ and $\mathrm{P}<0.001$, respectively). The methylation rate at $\mathrm{CpG}_{-} 1$ in the leukocytopenia group was significantly higher than that in the leukocytosis and normal control group $(\mathrm{P}=0.020$ and $\mathrm{P}=0.035$, respectively), although no significant difference was observed between the leukocytosis and normal control groups. The methylation rate at $\mathrm{CpG}_{-} 5 / 6$ in the leukocytopenia group was significantly higher than that in the leukocytosis $(\mathrm{P}=0.001)$, but no significant difference was observed between the leukocytosis group and the normal control group. In the leukocytopenia group, the methylation rate at $\mathrm{CpG}_{-} 7$ was significantly higher than that in the leukocytosis group and the normal control group $(\mathrm{P}<0.001$ and $\mathrm{P}=0.017$, respectively), and the rate in the leukocytosis group was significantly lower than that in the normal control group $(\mathrm{P}=0.013)$.

AKT2 gene. A total of five $\mathrm{CpG}$ sites among AKT2 fragments $\left(\mathrm{CpG}\right.$ _1, CpG_2, $\mathrm{CpG} \_3, \mathrm{CpG}_{-} 4$ and $\mathrm{CpG}$ _5) were investigated, and three $\left(\mathrm{CpG} \_1, \mathrm{CpG}_{-} 3\right.$ and $\left.\mathrm{CpG} \_5\right)$ were detected. 


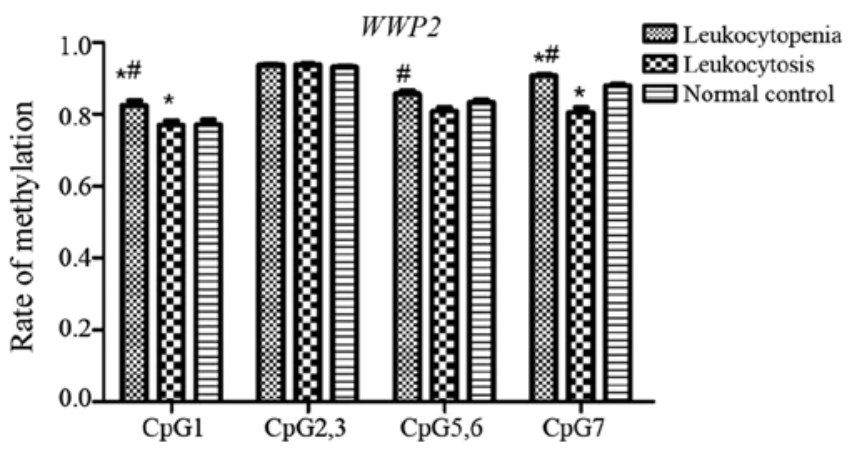

Figure 7. Comparison of methylation levels of WWP2 in peripheral blood from leukocytopenia, leukocytosis, and normal control groups. Data are presented as the mean rate \pm SD in the related group $(n=30)$. A Bonferroni correction was applied to all $\mathrm{P}$-values. ${ }^{*} \mathrm{P}<0.05$ vs. normal control; ${ }^{*} \mathrm{P}<0.05$ vs. leukocytosis. WWP2, WW domain containing E3 ubiquitin protein ligase 2; CpG, cytosine-phosphate-guanine.

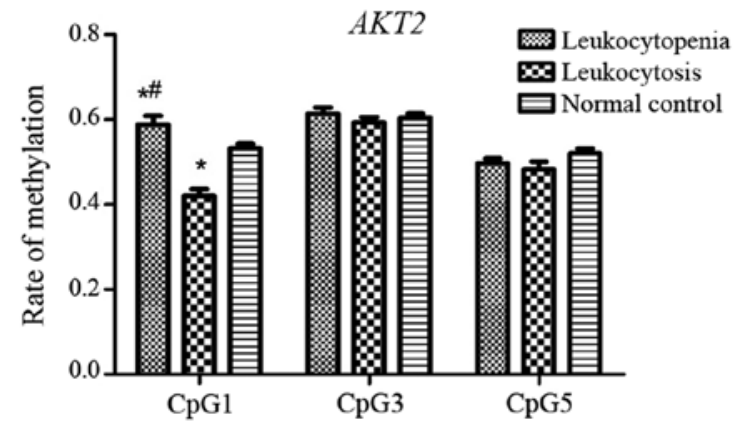

Figure 8. Comparison of methylation levels of AKT2 in peripheral blood from leukocytopenia, leukocytosis, and normal control groups. Data are presented as the mean rate \pm SD in the related group $(n=30)$. A Bonferroni correction was applied to all $\mathrm{P}$-values. ${ }^{*} \mathrm{P}<0.05$ vs. normal control; ${ }^{\#} \mathrm{P}<0.05$ vs. leukocytosis. CpG, cytosine-phosphate-guanine.

No significant differences in methylation levels at the $\mathrm{CpG}_{-} 3$ and CpG_5 sites were observed among the three groups ( $\mathrm{P}=0.581$ and $\mathrm{P}=0.215$, respectively); however, the levels of CpG_1 methylation in the leukocytopenia group were significantly higher than those in the leukocytosis and normal control groups $(\mathrm{P}<0.001$ and $\mathrm{P}=0.045$, respectively; Fig. 8$)$, and the leukocytosis group had a significantly lower methylation level at this site than the normal control group $(\mathrm{P}=0.001)$.

CBARAl gene. A total of four $\mathrm{CpG}$ sites among CBARAl fragments (CpG_1, CpG_2, CpG_3 and $\mathrm{CpG} \_4$ ) were investigated and detected. No significant differences in methylation at the $\mathrm{CpG}_{-} 1, \mathrm{CpG}_{-} 3$ and $\mathrm{CpG}_{-} 4$ sites were found among the three groups (all $\mathrm{P}>0.05$ ), whereas a significant difference was observed for $\mathrm{CpG} \_2\left(\mathrm{P}=0.011\right.$; Fig. 9). The $\mathrm{CpG} \_2$ methylation level in the leukocytosis group was significantly lower than that in the normal control group $(\mathrm{P}=0.002)$.

NOX5 gene. For NOX5 fragments $\left(\mathrm{CpG} \_1, \mathrm{CpG} \_2, \mathrm{CpG} \_3\right.$ and $\mathrm{CpG}_{-} 4$ ), four $\mathrm{CpG}$ sites were investigated and three (CpG_2, CpG_3 and $\mathrm{CpG}_{-} 4$ ) were detected. No significant differences in methylation levels at the $\mathrm{CpG}_{2} 2$ and $\mathrm{CpG}_{-} 4$ sites were observed among the three groups (both $\mathrm{P}>0.05$ ), whereas a significant difference was observed for $\mathrm{CpG}_{-} 3$ ( $P=0.005$; Fig. 10). The methylation level at the $\mathrm{CpG}_{-} 3$ in the

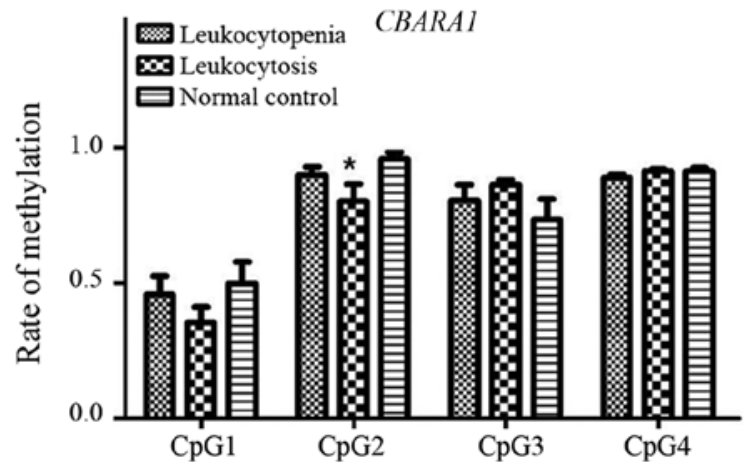

Figure 9. Comparison of methylation levels of CBARA1 in peripheral blood from leukocytopenia, leukocytosis, and normal control groups. Data are presented as the mean rate $\pm \mathrm{SD}$ in the related group $(n=30)$. A Bonferroni correction was applied to all P-values. ${ }^{*} \mathrm{P}<0.05$ vs. normal control. CBARA1, calcium-binding atopy-related autoantigen $1 ; \mathrm{CpG}$, cytosine-phosphate-guanine

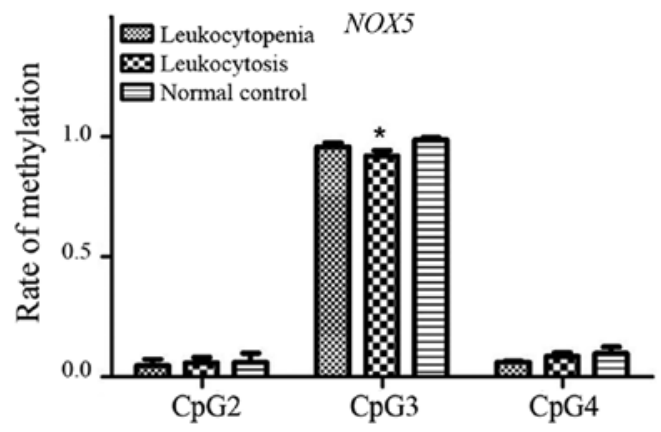

Figure 10. Comparison of methylation levels of NOX5 in peripheral blood from leukocytopenia, leukocytosis, and normal control groups. Data are presented as the mean rate $\pm S D$ in the related group $(n=30)$. A Bonferroni correction was applied to all P-values. ${ }^{*} \mathrm{P}<0.05$ vs. normal control. NOX5, NADPH oxidase 5; CpG, cytosine-phosphate-guanine.

leukocytosis group was significantly lower than that in the normal control group $(\mathrm{P}=0.004)$.

\section{Discussion}

Death due to infection is currently the cause of $\sim 25 \%$ of all deaths caused by diseases worldwide (1). In recent years, the incidence rate of infection has remained high for various reasons, including disease complications, the use of glucocorticoids, immunocompromise, bacterial resistance and invasive operations (1). Regardless of leukocytopenia or leukocytosis, infections are primarily caused by pathogens, commonly viruses and bacteria, which initiate infection by activating innate immunity. Non-specific innate immunity (30), also known as natural immunity, plays an important role in acute infection, and neutrophils, lymphocytes, eosinophils and basophils are important immunocytes involved in this process (31). These cells reach the site of infection via adhering, binding, cellular escape and cellular migration (32), and release reactive oxygen species and antimicrobial lytic proteins, such as peroxidase, lysozyme, alkaline phosphatase and acid hydrolase (33). These cells engulf, kill and digest microorganisms, thereby playing a direct role in the immune system (34). In clinical settings, post-infection leukocytopenia occurs frequently; the symptoms of patients with 
post-infection leukocytopenia are generally severe and difficult to treat, and require an extensive anti-infection treatment course (35). Furthermore, abnormalities such as cell migration disorders, myelosis, reduced chemotactic factor secretion and immunocyte surface receptor abnormalities may exist in these patients (36). In the present study, the general clinical data of patients with leukocytopenia, including age, sex, infection site, routine blood tests, and levels of IL-6 and serum complement, were analyzed and whole-genome methylation analysis was performed. Key sites of methylation were then screened with the aim of exploring post-infection leukocytopenia-associated molecular mechanisms in order to provide a novel avenue for gene diagnosis and treatment of such diseases.

The general data showed higher levels of PCT and IL-6 in the leukocytosis group compared with the leukocytopenia group. Furthermore, patients in the leukocytopenia group had a higher APACHE II score than those in the leukocytosis group, indicating a worse prognosis. Analysis of serum complement C3 and C5 levels revealed significant decreases in the leukocytopenia group compared with the leukocytosis and normal control groups. This finding suggested that post-infection leukocytopenia may be complicated by abnormally low expression of chemotactic factors, and that abnormal expression of chemotactic factors may partly contribute to the pathogenesis of infection-associated leukocytopenia. Genome methylation detection was then performed to further determine the mechanisms via which chemotactic factors are abnormally expressed, as well as to find other mechanisms underlying post-infection leukocytopenia.

DNA methylation is classically studied in epigenetic research and is the most representative feature of epigenetics. Moreover, changes in methylation may underlie the pathogenesis of a variety of diseases (37). In the present study, whole-genome methylation detection was performed, revealing significant enrichment in various pathways and disease-causing functions. The significantly enriched pathways and functions closely associated with the development of post-infection leukocytopenia included receptor activity, transmembrane signal transduction and potassium ion channels. These results indicated that multiple pathways are responsible for the development of this disease via network interactions. Diseases with significant enrichment included cancer, neurodegenerative disorders, intestinal diseases, cardiovascular diseases, endocrine diseases and urinary diseases, although most of these were not associated with the disease investigated in the present study. This may be partially due to the fact that genome methylation detection is primarily applied in research into tumors, as well as cardiovascular and nervous system diseases $(38,39)$, whereas its application in investigating infectious disease has not been reported to date. In addition, this finding may also be due to limitations such as small sample size and experimental error. Therefore, experiments with a larger sample size should be performed in the future to obtain more accurate functional enrichment analysis data.

Intersection analysis of differentially methylated gene sites between the leukocytopenia and leukocytosis groups, and the leukocytopenia and normal control groups may suggest the cause of leukocytopenia, and that between the leukocytopenia and leukocytosis groups, and the leukocytosis and normal control groups may indicate the cause of leukocytosis. Based on reports from the literature and P-values obtained, NOX5, WWP2, AKT2 and CBARAl were selected for further verification. NOX5 is expressed in the spleen and lymph node cells (40), and its functions primarily include calcium ion binding, hydrogen ion channels, superoxide production, NADPH oxidase, oxidoreductase, flavin adenine dinucleotide binding and NADP binding (41). NOX5 protein primarily participates in cytokinesis, electron transfer, apoptosis, cellular proliferation, proton transportation regulation, superoxide release, cytokine secretion and cell fusion regulation (42). According to a previous study (43), monocytes can differentiate into various subsets of dendritic cells, and NOX5-p22phox complexes may promote the differentiation of monocytes into dendritic cells via Janus kinase/signal transducers, and activators of transcription/MAPK and NF- $x$ B pathways. NOX5 may be able to reduce oxidative stress and may be associated with calcium ion channel-related oxidative stress in lymph nodes (44). WWP2 also exhibits protein binding and ligase activities (28); it is involved in the ubiquitination process, circulation and viral entry into host cells (28). WWP2 has a negative regulatory effect on Toll-like receptor 3-mediated innate immunity (45). CBARA1 has calcium ion-binding activity and participates in the immune response (26). AKT2 shows nucleotide-binding, protein serine, threonine kinase, protein-binding, ATP-binding and transferase activities, and participates in protein amino acid phosphorylation as well as the development of diabetes $(46,47)$. Moreover, it has been shown that AKT2 is associated with dendritic cell migration and the functions of neutrophils, as well as vascular permeability, edema and leukocytic emigration in acute inflammation (48). AKT2 knockout can ameliorate pulmonary injury by reducing alveolar cell depolarization (49), and AKT2 may also participate in the development of pulmonary fibrosis via transforming growth factor- $\beta 1$ and IL-13 (50).

The present study has a number of limitations. First, the sample used for genome methylation detection was small, which may have resulted in false positive results. Therefore, these findings need to be further verified by experiments with larger sample sizes. Second, as most studies into methylation and genomes have focused on tumor research, signaling pathway analysis and disease enrichment analysis in this study, based on the current datasets, did not identify the direct association of the methylated genes with leukocytopenia. Therefore, studies involving animal experiments and gene knockout need to be performed in the future.

In conclusion, four genes may participate in the occurrence of leukocytopenia after infection: NOX5, WWP2, AKT2 and CBARA1. Based on the results of this study, multiple experiments with larger sample sizes should be carried out and more genes should be selected for verification. These experiments may be useful for clarifying the molecular mechanisms underlying leukocytopenia following infection, and identifying novel strategies for diagnosis and treatment.

\section{Acknowledgements}

Not applicable. 


\section{Funding}

The present study was financially supported by the Youth Fund of the Natural Science Foundation of Xinjiang Uygur Autonomous Region (grant no. 2015211C214).

\section{Availability of data and materials}

The datasets used and/or analyzed during the present study are available from the corresponding author on reasonable request.

\section{Authors' contributions}

All authors have made contributions to the current work. $\mathrm{CW}$ and $\mathrm{XY}$ designed the study. CW led the writing of the article. XM, WW, MD, and RJ conducted the experiments and collected the data. ZL, DL and YL conducted data analysis. XY supervised the process and offered constructive advice. All authors read and approved the final manuscript.

\section{Ethics approval and consent to participate}

This study was conducted in accordance with the Declaration of Helsinki. Approval was obtained from the Ethics Committee of People's Hospital of Xinjiang Uygur Autonomous Region (policy no. 2016056). Written informed consent was obtained from each participant.

\section{Patient consent for publication}

Not applicable.

\section{Competing interests}

The authors declare that they have no competing interests.

\section{References}

1. Xu R: Global dynamics of an epidemiological model with age of infection and disease relapse. J Biol Dyn 12: 118-145, 2018.

2. Panupattanapong S, Stwalley DL, White AJ, Olsen MA, French AR and Hartman ME: Epidemiology and outcomes of granulomatosis with polyangiitis in pediatric and working-age adult populations In the United States: Analysis of a large national claims database. Arthritis Rheumatol 70: 2067-2076, 2018.

3. Tendl KA, Schulz SMF, Mechtler TP, Bohn A, Metz T, Greber-Platzer S, Kasper DC, Herkner KR and Item CB: DNA methylation pattern of CALCA in preterm neonates with bacterial sepsis as a putative epigenetic biomarker. Epigenetics 8: 1261-1267, 2013.

4. Dhas DB, Ashmi AH, Bhat BV, Kalaivani S and Parija SC: Comparison of genomic DNA methylation pattern among septic and non-septic newborns - An epigenome wide association study. Genom Data 3: 36-40, 2014.

5. Saif I, Kasmi Y, Allali K and Ennaji MM: Prediction of DNA methylation in the promoter of gene suppressor tumor. Gene 651: 166-173, 2018

6. Bomsztyk K, Denisenko O and Wang Y: DNA methylation yields epigenetic clues into the diabetic nephropathy of Pima Indians. Kidney Int 93: 1272-1275, 2018.

7. Samadian A, Hesaraki M, Mollamohammadi S, Asgari B, Totonchi $\mathrm{M}$ and Baharvand $\mathrm{H}$ : Temporal gene expression and DNA methylation during embryonic stem cell derivation. Cell J 20: 361-368, 2018.

8. Beck S, Rhee C and Song J: Temporal Gene Expression and DNA Methylation during Embryonic Stem Cell Derivation. Nucleic Acids Res 46: 4382-4391, 2018.
9. Zare M, Bastami M, Solali S and Alivand MR: Aberrant miRNA promoter methylation and EMT-involving miRNAs in breast cancer metastasis: Diagnosis and therapeutic implications. J Cell Physiol 233: 3729-3744, 2018.

10. Dixit AB, Sharma D, Tripathi M, Srivastava A, Paul D, Prakash D, Sarkar C, Kumar K, Banerjee J and Chandra PS: Genome-wide DNA methylation and RNAseq analyses identify aberrant signalling pathways in focal cortical dysplasia (FCD) type II. Sci Rep 12: 17976, 2018

11. Mohammadi NM, Shamsasenjan K and Akbarzadehlaleh P: The angiogenic chemokines expression profile of myeloid cell lines co-cultured with bone marrow-derived mesenchymal stem cells. Cell J 20: 19-24, 2018.

12. Zou LS, Erdos MR, Taylor DL, Chines PS, Varshney A, Parker SCJ, Collins FS and Didion JP; McDonnell Genome Institute: BoostMe accurately predicts DNA methylation values in whole-genome bisulfite sequencing of multiple human tissues. BMC Genomics 19: 390-403, 2018.

13. FarajifardH,Zavvar M,RajaeiT,NoorbakhshF,Nikougoftar-ZarifM, Azadmanesh K, Kompani F and Rezaei N: In vitro study of HAX1 gene therapy by retro viral transduction as a therapeutic target in severe congenital neutropenia. Eur Cytokine Netw 29: 146-152, 2018.

14. Tyner C,Barber GP,Casper J,Clawson H,Diekhans M,EisenhartC, Fischer CM, Gibson D, Gonzalez JN, Guruvadoo L, et al: The UCSC Genome Browser database: 2017 update. Nucleic Acids Res 45 (D1): D626-D634, 2017.

15. Chrzastek K, Lee DH, Smith D, Sharma P, Suarez DL, Pantin-Jackwood M and Kapczynski DR: Use of sequence-independent, single-primer-amplification (SISPA) for rapid detection, identification, and characterization of avian RNA viruses. Virology 509: 159-166, 2017.

16. Reese SE, Zhao S, Wu MC, Joubert BR, Parr CL, Håberg SE, Ueland PM, Nilsen RM, Midttun $\varnothing$, Vollset SE, et al: DNA methylation score as a biomarker in newborns for sustained maternal smoking during pregnancy. Environ Health Perspect 125: 760-766, 2017.

17. Shen J, Wang S, Zhang YJ, Wu HC, Kibriya MG, Jasmine F, Ahsan H, Wu DP, Siegel AB, Remotti H, et al: Exploring genome-wide DNA methylation profiles altered in hepatocellular carcinoma using infinium humanmethylation 450 beadchips. Epigenetics 8: 34-43, 2013.

18. Deng X, Yang Y, Sun H, Qi W, Duan Y and Qian Y: Analysis of whole genome-wide methylation and gene expression profiles in visceral omental adipose tissue of pregnancies with gestational diabetes mellitus. J Chin Med Assoc 81: 623-630, 2018.

19. Kunze S: Quantitative region-specific DNA methylation analysis by the EpiTYPERTM Technology. Methods Mol Biol 1708: 515-535, 2018.

20. R Core Team: R: A language and environment for statistical computing. R Foundation for Statistical Computing, Vienna, Austria. 2014. http://www.R-project.org/.

21. Du P, Kibbe WA and Lin SM: lumi: A pipeline for processing Illumina microarray. Bioinformatics 24: 1547-1548, 2008.

22. Wang D, Yan L,Hu Q, Sucheston LE, Higgins MJ, Ambrosone CB, Johnson CS, Smiraglia DJ and Liu S: IMA: An R package for high-throughput analysis of Illumina's $450 \mathrm{~K}$ Infinium methylation data. Bioinformatics 28: 729-730, 2012.

23. Ritchie ME, Phipson B, Wu D, Hu Y, Law CW, Shi W and Smyth GK: limma powers differential expression analyses for RNA-sequencing and microarray studies. Nucleic Acids Res 43: e47, 2015

24. Benjamini Y and Hochberg Y: Controlling the false discovery rate: A practical and powerful approach to multiple testing. J R Stat Soc B 51: 289-300, 1995.

25. Ashburner M, Ball CA, Blake JA, Botstein D, Butler H, Cherry JM, Davis AP, Dolinski K, Dwight SS, Eppig JT, et al; The Gene Ontology Consortium: Gene ontology: Tool for the unification of biology. Nat Genet 25: 25-29, 2000.

26. The Gene Ontology Consortium: The Gene Ontology Resource: 20 years and still GOing strong. Nucleic Acids Res 47 (D1): D330-D338, 2019.

27. Kanehisa M, Sato Y, Furumichi M, Morishima K and Tanabe M: New approach for understanding genome variations in KEGG. Nucleic Acids Res 47 (D1): D590-D595, 2019.

28. Chen K, Hsu LT, Wu CY, Chang SY, Huang HT and Chen W: CBARA1 plays a role in stemness and proliferation of human embryonic stem cells. PLoS One 8: e63653, 2013.

29. Zou G, Liu T, Guo L, Huang Y,Feng Y and Duan T: MicroRNA-32 silences WWP2 expression to maintain the pluripotency of human amniotic epithelial stem cells and $\beta$ islet-like cell differentiation. Int J Mol Med 41: 1983-1991, 2018 
30. Gerdol M, Luo YJ, Satoh N and Pallavicini A: Genetic and molecular basis of the immune system in the brachiopod Lingula anatina. Dev Comp Immunol 82: 7-30, 2018.

31. Iqbal J, El-Gamal MI, Ejaz SA, Lecka J, Sévigny J and Oh CH: Tricyclic coumarin sulphonate derivatives with alkaline phosphatase inhibitory effects: In vitro and docking studies. J Enzyme Inhib Med Chem 33: 479-484, 2018.

32. Mohammadi H, Sharafkandi N, Hemmatzadeh M, Azizi G, Karimi M, Jadidi-Niaragh F, Baradaran B and Babaloo Z: The role of innate lymphoid cells in health and disease. J Cell Physiol 233: 4512-4529, 2018.

33. Sheikh AA, Hooda OK and Dang AK: JAK3 and PI3K mediate bovine Interferon-tau stimulated gene expression in the blood neutrophils. J Cell Physiol 233: 4885-4894, 2018.

34. Nowak K, Ratajczak-Wrona W, Garley M and Jabłońska E: The effect of ethanol and N-nitrosodimethylamine on the iNOS-dependent NO production in human neutrophils. Role of NF- $x$ B. Xenobiotica 48: 498-505, 2018.

35. Komatsu H, Hayashi K and Higashiyama F: Treatment with granulocyte colony-stimulating factor in the refeeding phase of anorexia nervosa complicated with severe neutropenia and sepsis: A case report. Eat Weight Disord 23: 897-902, 2018.

36. Kumari P and Kumar H: Viral deubiquitinases: Role in evasion of anti-viral innate immunity. Crit Rev Microbiol 44: 304-317, 2018.

37. Sun W, Guo F and Liu M: Up-regulated WDR5 promotes gastric cancer formation by induced cyclin D1 expression. J Cell Biochem 119: 3304-3316, 2018.

38. Lu TP, Chuang NC, Cheng CY, Hsu CA, Wang YC, Lin YH, Lee JK, Wu CK, Hwang JJ, Lin LY, et al: Genome-wide methylation profiles in coronary artery ectasia. Clin Sci (Lond) 131: 583-594, 2017.

39. Yamada Y, Horibe H, Oguri M, Sakuma J, Takeuchi I, Yasukochi Y, Kato K and Sawabe M: Identification of novel hyper- or hypomethylated $\mathrm{CpG}$ sites and genes associated with atherosclerotic plaque using an epigenome-wide association study. Int J Mol Med 41: 2724-2732, 2018.

40. Ghanbari H, Keshtgar S and Kazeroni M: Inhibition of the CatSper channel and NOX5 enzyme activity affects the functions of the progesterone-stimulated human sperm. Iran J Med Sci 43: 18-25, 2018.

41. Mahbouli S, Der Vartanian A, Ortega S, Rougé S, Vasson MP and Rossary A: Leptin induces ROS via NOX5 in healthy and neoplastic mammary epithelial cells. Oncol Rep 38: 3254-3264, 2017.

42. Jha JC, Watson AMD, Mathew G, de Vos LC and Jandeleit-Dahm K: The emerging role of NADPH oxidase NOX5 in vascular disease. Clin Sci (Lond) 131: 981-990, 2017.
43. Dho SH, Kim JY, Lee KP, Kwon ES, Lim JC, Kim CJ, Jeong D and Kwon KS: STAT5A-mediated NOX5-L expression promotes the proliferation and metastasis of breast cancer cells. Exp Cell Res 351: 51-58, 2017.

44. Oliva-Olivera W, Moreno-Indias I, Coín-Aragüez L, Lhamyani S, Alcaide Torres J, Fernández-Veledo S, Vendrell J, Camargo A, El Bekay R and Tinahones FJ: Different response to hypoxia of adipose-derived multipotent cells from obese subjects with and without metabolic syndrome. PLoS One 12: e0188324, 2017.

45. Liu J, Wan L, Liu J, Yuan Z, Zhang J, Guo J, Malumbres M, Liu J, Zou W and Wei W: Cdh1 inhibits WWP2-mediated ubiquitination of PTEN to suppress tumorigenesis in an APC-independent manner. Cell Discov 2: 15044-15053, 2016.

46. Smet-Nocca C, Page A, Cantrelle FX, Nikolakaki E, Landrieu I and Giannakouros T: The O- $\beta$-linked $N$-acetylglucosaminylation of the Lamin B receptor and its impact on DNA binding and phosphorylation. Biochim Biophys Acta, Gen Subj 1862: 825-835, 2018

47. Gu J, Yan X, Dai X, Wang Y, Lin Q, Xiao J, Zhou S, Zhang J, Wang K, Zeng J, et al: Metallothionein preserves Akt2 activity and cardiac function via inhibiting TRB3 in diabetic hearts. Diabetes 67: 507-517, 2018.

48. Sudhahar V, Okur MN, Bagi Z, O'Bryan JP, Hay N, Makino A Patel VS, Phillips SA, Stepp D, Ushio-Fukai M, et al: Akt2 (protein kinase B beta) stabilizes ATP7A, a copper transporter for extracellular superoxide dismutase, in vascular smooth muscle: Novel mechanism to limit endothelial dysfunction in type 2 diabetes mellitus. Arterioscler Thromb Vasc Biol 38: 529-541, 2018.

49. Trejo-Soto PJ, Hernández-Campos A, Romo-Mancillas A, Medina-Franco JL and Castillo R: In search of AKT kinase inhibitors as anticancer agents: Structure-based design, docking, and molecular dynamics studies of 2,4,6-trisubstituted pyridines. J Biomol Struct Dyn 36: 423-442, 2018.

50. Nie Y, Sun L, Wu Y, Yang Y, Wang J, He H, Hu Y, Chang Y, Liang Q, Zhu J, et al: AKT2 regulates pulmonary inflammation and fibrosis via modulating macrophage activation. $J$ Immunol 198: 4470-4480, 2017.

(i) $($ This work is licensed under a Creative Commons Attribution-NonCommercial-NoDerivatives 4.0 International (CC BY-NC-ND 4.0) License. 